\title{
AS INTERAÇÕES DISCURSIVAS NO ENSINO DE FÍSICA: A PROMOÇÃO DA DISCUSSÃO PELO PROFESSOR E A ALFABETIZAÇÃO CIENTÍFICA DOS ALUNOS
}

\section{Discursive interactions in science education: teacher's promotion of discussion and student's scientific literacy}

\author{
Vitor Fabrício Machado Souza ${ }^{1}$ • Lucia Helena Sasseron ${ }^{2}$
}

\begin{abstract}
Resumo: Neste trabalho propomos uma análise comparativa entre o discurso do professor e os indicadores de Alfabetização Científica apontados no discurso dos alunos, de modo a buscar uma relação entre a ação do professor e o desenvolvimento de habilidades visadas no ensino de ciências. Investigaremos as interações discursivas em sala de aula de Física do Ensino Médio utilizando duas metodologias de análise: a primeira visa a identificar as interações do professor, suas intenções, o conteúdo do discurso, as formas de abordagem, os padrões discursivos e as intervenções. A segunda, busca identificar, no discurso dos alunos, parâmetros de organização, seriação ou classificação de informações, elaboração e teste de hipóteses, raciocínio lógico, justificativa, previsão e explicação. Verificamos, dentre outras coisas, a relação direta entre o padrão discursivo do professor e o desenvolvimento de habilidades científicas relevantes a um ensino que vise a Alfabetização Científica.
\end{abstract}

Palavras-chave: Interações discursivas. Alfabetização científica. Ensino de ciências. Discurso do professor.

\begin{abstract}
In this paper we propose a comparative analysis between the discourse of the teacher and the indicators of Scientific Literacy in order to seek a relationship between the action of the teacher and the development of skills aimed at teaching science. We will analyze the discursive interactions in high school classroom of Physics by using two analysis methods: the first, aims to identify the interactions of the teacher, his intentions, the content of speech, ways to approach the standards for discourse and action. The second, seeks to identify, into student's speech, parameters of organization, ranking or classification of information, developing and testing hypotheses, logical reasoning, explanation, prediction and explanation. We checked out other things to direct relationship between the standard discourse of the teacher and the development of skills relevant to a scientific education that aims to Scientific Literacy.
\end{abstract}

Keywords: Discursive interactions. Scientific literacy. Science education. Teacher's speech. Argument

\footnotetext{
${ }^{1}$ Programa de Pós-Graduação Interunidades, modalidade ensino de Física, Universidade de São Paulo (USP). Avenida da Universidade, 308, bloco B, sala 3. São Paulo, SP, Brasil. 05.508-900.vitorfms@usp.br

${ }^{2}$ Faculdade de Educação, USP. São Paulo, SP, Brasil.
} 
Souza, V. F. M.; Sasseron, L. H.

\section{Introdução}

A sala de aula é um ambiente dinâmico no que se refere às interações entre alunos e seus pares; alunos e professores; e alunos, professores e os objetos de aprendizagem. De acordo com Vigotsky (2000), é por meio dessas interações que o conhecimento se constrói. A grande maioria das interações em sala é mediada pela linguagem. E, ainda de acordo com Vigotsky (2000) e Bakthin (2000), há uma relação íntima entre a linguagem e o desenvolvimento do pensamento, ou seja, é por meio da estruturação da linguagem que se concebe um significado, e por meio das articulações desses significados que a aprendizagem se dá em relação ao mundo. Esse pensamento é amplamente discutido e aceito desde meados da década de 1960 com a linha de estudo da cognição humana chamada de "construtivismo", de caráter sociointeracionista exatamente pela necessidade de os sujeitos colocarem suas linguagens em torno de um objeto de conhecimento e negociarem os significados para ele. Dessa linha de pensamento emerge a necessidade de se estudarem as interações que ocorrem em sala de aula e a forma como alunos e professores constroem um sentido para um conceito.

Desde o fim da década de 1980, o estudo sobre as interações discursivas e da linguagem tem crescido em diversas áreas do conhecimento. No ensino de Ciências, são expoentes desse estudo os trabalhos de: Mortimer e Scott (2002), Lemke (1998), Driver, Newton e Osborne (2000), Nascimento e Vieira (2009), Sasseron e Carvalho (2008), Roth (2003), JiménezAleixandre, Bugallo Rodríguez e Duschl (2000), Martins, Ogborn e Kress (1999), entre outros. Todas essas pesquisas acordam sobre a importância da linguagem e das interações discursivas em consonância com as perspectivas construtivistas de aprendizagem e com uma visão mais ampla sobre o sentido de se ensinar Ciência como uma cultura, como um modo de pensar e agir na sociedade; visão que se faz presente nos principais currículos mundiais de ensino de Ciências (RODRIGUES; BORGES, 2008; MILLAR; OSBORNE, 1998; OLSON; LOUCKSHOSLEY, 2000). As interações discursivas são consideradas como constituintes do processo de construção de significados (MORTIMER; SCOTT, 2002), que apresentam múltiplos sentidos e vozes criados na interação social e internalizados pelos indivíduos. Lemke (1998) destaca os diferentes tipos de linguagens existentes no ensino de ciências, tais como gráficos, diagramas, tabelas, e que a aprendizagem em Ciências engloba o domínio e diferenciação dessas linguagens. Martins, Ogborn e Kress (1999) expõem que aprender Ciências, necessariamente, exige o emprego de uma pluralidade de meios de comunicação de forma coordenada, e a construção de novas significações resulta, também, da interação dos diversos sistemas de representação. A autora aponta, ainda, que a forma de se conseguir essa pluralidade de meios em sala de aula passa, necessariamente, pela interação entre os sujeitos envolvidos. Para que isso ocorra, as atividades implementadas devem privilegiar as discussões, os debates, as exposições de ideias e percepções dos alunos diante de um conceito ou fenômeno. Em suma, devem ser problematizadoras. Esse sentido de atividade problematizadora é delimitado por Gil-Pérez et al. (1992). Para os autores, um problema consiste de situações dificultosas, para as quais não existem soluções fechadas; uma situação, quantitativa ou não, que pede aos sujeitos envolvidos uma solução que não é evidente. Ainda nesse trabalho, os autores defendem que o modo pelo qual um cientista resolve um problema é pela investigação científica: competência primordial para o ensino de Ciências. 
As interações discursivas no ensino de Física: ...

\section{A alfabetização científica e as interações discursivas no ensino de ciências}

Essa perspectiva de se ensinar Ciências privilegiando a resolução de problemas, o pensar científico, o uso das múltiplas linguagens, da argumentação como habilidade científica, é encontrada, na literatura, como Alfabetização Científica ou Enculturação Científica, ou até Letramento Científico. Utilizaremos, neste trabalho, o nome de Alfabetização Científica (AC). Em diversos trabalhos da Didática das Ciências, percebemos uma variação no uso do termo que define o ensino de Ciências preocupado com a formação cidadã dos alunos para ação e atuação em sociedade. Autores de língua espanhola, por exemplo, costumam utilizar a expressão "Alfabetización Científica" para designar o ensino cujo objetivo seria a promoção de capacidades e competências, entre os estudantes, capazes de permitir-lhes a participação nos processos de decisões do dia a dia (MEMBIELA, 2007; DÍAZ; ALONSO; MAS, 2003; CAJAS, 2001; GIL-PÉREZ; VILCHES-PEÑA, 2001); nas publicações em língua inglesa o mesmo objetivo aparece sob o termo "Scientific Literacy" (NORRIS; PHILLIPS, 2003; LAUGKSCH, 2000; HURD, 1998; BYBEE, 1995; BINGLE; GASKELL, 1994; BYBEE; DeBOER, 1994); e, nas publicações francesas, encontramos o uso da expressão "Alphabétisation Scientifique" (FOUREZ, 1994, 2000; ASTOLFI, 1995).

Para nós, cuja língua materna é a portuguesa, o problema ganha novas proporções quando da tradução dos termos: a expressão inglesa vem sendo traduzida como "Letramento Científico", enquanto as expressões francesa e espanhola, literalmente falando, significam "Alfabetização Científica".

Devido à pluralidade semântica, encontramos, hoje em dia, na literatura nacional sobre ensino de Ciências, autores que utilizam a expressão "Letramento Científico" (MAMEDE; ZIMMERMANN, 2005; SANTOS; MORTIMER, 2001); pesquisadores que adotam o termo "Alfabetização Científica" (BRANDI; GURGEL, 2002; AULER; DELIZOICOV, 2001; LORENZETTI; DELIZOICOV, 2001; CHASSOT, 2000), e também aqueles que usam a expressão "Enculturação Científica" (CARVALHO; TINOCO, 2006; MORTIMER; MACHADO, 1996) para designarem o objetivo deste ensino de Ciências que almeja a formação cidadã dos estudantes para o domínio e uso dos conhecimentos científicos e seus desdobramentos nas mais diferentes esferas de sua vida. Podemos perceber que, no cerne das discussões levantadas pelos pesquisadores que usam um termo ou outro, estão as mesmas preocupações com o ensino de Ciências, ou seja, motivos que guiam o planejamento deste ensino para a construção de benefícios práticos para as pessoas, a sociedade e o meio ambiente.

Os autores brasileiros que usam a expressão "Enculturação Científica" partem do pressuposto de que o ensino de Ciências pode e deve promover condições para que os alunos, além das culturas religiosa, social e histórica que carregam consigo, possam também fazer parte de uma cultura em que as noções, ideias e conceitos científicos são parte de seu corpus. Deste modo, seriam capazes de participar das discussões desta cultura, obtendo informações e fazendo-se comunicar.

Os pesquisadores nacionais que preferem a expressão "Letramento Científico" justificam sua escolha apoiando-se no significado do termo defendido por duas grandes pesquisadores da Linguística: Angela Kleiman e Magda Soares. Soares (1998, p. 18) define o letramento como sendo: "[...] resultado da ação de ensinar ou aprender a ler e escrever: estado ou 
condição que adquire um grupo social ou um indivíduo como conseqüência de ter-se apropriado da escrita."

Kleiman $(1995$, p. 19) comenta sobre a complexidade do conceito, mas adota sua definição como sendo o "conjunto de práticas sociais que usam a escrita enquanto sistema simbólico e enquanto tecnologia, em contextos específicos para objetivos específicos."

Utilizamos a expressão "Alfabetização Científica" alicerçados na ideia de alfabetização concebida por Paulo Freire (1980, p. 111): “[...] a alfabetização é mais que o simples domínio psicológico e mecânico de técnicas de escrever e de ler. É o domínio destas técnicas em termos conscientes. [...] Implica numa autoformação de que possa resultar uma postura interferente do homem sobre seu contexto".

Assim pensando, a alfabetização deve desenvolver, em uma pessoa qualquer, a capacidade de organizar seu pensamento de maneira lógica, além de auxiliar na construção de uma consciência mais crítica em relação ao mundo que a cerca.

Neste trabalho, defendemos uma concepção de ensino de Ciências que pode ser vista como um processo de "enculturação científica" dos alunos, no qual esperaríamos promover condições para que os alunos fossem inseridos em mais uma cultura, a cultura científica. Tal concepção também poderia ser entendida como um "letramento científico", se o consideramos como o conjunto de práticas das quais uma pessoa lança mão para interagir com seu mundo e os conhecimentos dele. No entanto, usaremos o termo "alfabetização científica" para designar as ideias que temos em mente e que objetivamos ao planejarmos um ensino que permita aos alunos interagirem com uma nova cultura, com uma nova forma de ver o mundo e seus acontecimentos, podendo modificá-lo e a si próprios através da prática consciente propiciada por sua interação cerceada de saberes, de noções e conhecimentos científicos, bem como das habilidades associadas ao fazer científico.

O alfabetizado cientificamente, assim como um cientista, não precisa saber tudo sobre as Ciências, mas deve ter conhecimentos suficientes de vários de seus campos e saber sobre como esses estudos se transformam em adventos para a sociedade, no sentido de compreender de que modo tais conhecimentos podem afetar sua vida e a do planeta. O foco deixa de estar somente no ensino de conceitos e métodos das Ciências, mas também sobre a natureza das Ciências e suas implicações mútuas com a sociedade e o ambiente. Para Driver, Newton e Osborne (2000), a Ciência é muito mais do que um conjunto de conhecimentos específicos ordenados em teorias; ela deve ser entendida como uma cultura que tem suas regras, valores e linguagem própria. Ademais, essa apreciação da Ciência, por parte dos alunos, é fundamentalmente construída nas interações em sala de aula. "É apenas pela interação em curso que o professor e os alunos têm a oportunidade de comparar interpretações do que estão dizendo uns aos outros, e assim aproxima-se gradualmente de significados funcionalmente equivalentes" (DRIVER; NEWTON; OSBORNE, 2000, p. 13).

E é por meio da linguagem e das interações discursivas que professores e alunos constroem as bases para um ensino cuja proposta privilegie a Ciência como uma cultura e vise à Alfabetização Científica. Além disso, é importante ressaltar que a adoção dos referenciais sobre o uso das linguagens nos permite compreender de que modo a construção do conhecimento em sala de aula é mediada pelo professor. A aprendizagem científica também é um processo de transição dialógica de uma linguagem abstrata e comum para uma linguagem científica, com suas características particulares, sendo que as linguagens não são excludentes, 
e sim complementares, em vista de suas significações simbólicas. Nessa perspectiva, o professor tem papel importante para construir e incentivar o uso da linguagem científica em seu trabalho docente.

Buscando entender melhor o papel discursivo do professor, propomos, neste artigo, uma análise das interações discursivas em uma aula de Física, relacionando-a com indicadores da Alfabetização Científica pelos alunos. Buscaremos responder a seguinte questão: quais e como são os tipos de ações discursivas do professor que se relacionam com a promoção dos indicadores da AC pelos alunos?

\section{A análise das interações discursivas e da promoção da Alfabetização Científica}

\section{As interações discursivas}

Utilizaremos, como referência neste trabalho, a pesquisa de Mortimer e Scott (2002), na qual é proposta uma metodologia de análise do discurso para se entender como ocorrem as interações professor-aluno em sala de aula. De acordo com essa elaboração, o discurso no referencial Bakhtiniano é tido por gêneros. Este se constitui de tipos estáveis de enunciados no qual cada esfera da linguagem é usada na interação. A análise do discurso por Mortimer e Scott (2002) abrange o papel do professor no que tange ao discurso em três grandes categorias que o influenciam: I) os focos do ensino, que abrangem as intenções do professor, ou seja, qual o problema proposto; como ele foi pensado; de que forma o professor utilizará as concepções prévias dos alunos; como ele pretende guiar a atividade. Outra perspectiva do foco de ensino é o conteńdo do discurso em sala de aula, que pode ser uma explicação, uma descrição ou uma generalização; II) a abordagem do professor, que fornece informações para a análise sobre como o professor trabalha as intenções e o conteúdo do ensino por meio das diferentes intervenções pedagógicas que resultam em padrões de interação. As formas de abordagem podem ser basicamente: dialógica, em que se contrapõem posições diferentes acerca do conteúdo; de autoridade, que apresenta uma visão única; interativa, na qual os alunos e o professor interagem na discussão; e não interativa, em que o professor discursa sozinho. Essas formas de abordagem não são excludentes, de modo que um professor pode ter um modo de abordagem dialógico e não interativo, ou seja, só ele imprime o discurso e contrapõe pontos de vista; III) as ações do professor, que se referem ao desenvolvimento da aula e os movimentos discursivos implicados nas interações. Foram chamados de padrão discursivo (IRF), no qual o professor elabora uma iniciação (I), os alunos dão uma resposta $(\mathrm{R})$ e o professor, um feedback (F). Esses padrões podem continuar e, normalmente, contêm a intenção do professor em guiar as posições do aluno frente ao fenômeno ou conteúdo. Por último, as interações também são influenciadas pelas intervenções do professor diante de uma pergunta ou uma colocação. Essas intervenções podem dar forma aos significados, ou seja, aprimorá-los em uma palavra ou nome correto; selecioná-los diferenciando os muito significados em uma exposição, marcá-los ou reforçá-los com uma expressão afirmativa, por exemplo; e compartilhá-los ou enunciá-los ao conjunto da sala, de modo que marquem o significado; verificar a compreensão dos alunos, interjeições ou perguntas; e rever os procedimentos feitos até o momento da aula. 
Souza, V. F. M.; Sasseron, L. H.

\section{Alfabetização Científica (AC)}

O delineamento conceitual de Alfabetização Científica a ser utilizado advém da pesquisa de Sasseron (2008): a partir da revisão da literatura específica sobre a AC, a autora identificou elementos e características a serem consideradas quando do planejamento de um ensino que tenha, como objetivo, a promoção da inserção dos estudantes no processo de alfabetização científica. Para analisar de que modo tal processo ocorre, a autora propôs a existência de indicadores de Alfabetização Científica que podem ser entendidos como habilidades investigativas utilizadas na construção de conhecimento. Segundo a autora, os indicadores estão associados: (a) ao trabalho com dados na seriação, classificação e organização de informações; (b) ao levantamento e teste de hipóteses; (c) à construção de explicações, uso de justificativas e estabelecimento de previsões; e (d) ao uso do raciocínio lógico e raciocínio proporcional como forma de tornar uma ideia mais coerente.

Em um outro trabalho, Sasseron e Carvalho (2011), utilizando os indicadores de AC para analisar o processo argumentativo ocorrido em aulas do Ensino Fundamental, constataram um padrão na presença e no aparecimento destes indicadores. A este padrão, as autoras dão o nome de ciclo argumentativo, entendendo-o como a forma por meio da qual as argumentações se desencadeiam e a maneira como as relações entre diferentes dados e variáveis são estabelecidas.

Este ciclo ocorreria no desenvolvimento de alguns passos dados ao longo de uma investigação. O primeiro deles seria o cuidado com os dados existentes e se caracterizaria pela ordenação de informações de modo a tornar convenientemente explícita a importância de cada uma em cada momento e situação. O segundo passo centra-se na identificação das variáveis que são verdadeiramente relevantes para um problema. Sasseron e Carvalho (2011) afirmam que, neste momento, começam a ser mencionadas as primeiras hipóteses. Ao mesmo tempo, justificativas são acrescentadas às afirmações feitas, bem como aparecem algumas previsões sobre o que pode ocorrer caso a ideia arquitetada se sustente. Segundo as autoras, o ciclo argumentativo se encerraria para um determinado tema na sala de aula quando as explicações propriamente ditas começassem a ser explicitadas pelos alunos. Neste momento, todas as construções feitas anteriormente são utilizadas com o objetivo de se estabelecerem conexões entre as informações e as variáveis, pois, deste modo, obtém-se uma ideia mais concreta de como os efeitos vistos e/ou previstos ocorrem. É possível, então, chegar a construções lógicas, objetivas e racionais entre causas e efeitos e, portanto, possuir conhecimentos por meio dos quais os benefícios e prejuízos de cada situação sejam também investigados.

Em outro estudo, cuja preocupação está no processo de Alfabetização Científica, Carvalho (2008) aponta para a necessidade de se ter mais elementos para formar e preparar professores capazes de colocar boas perguntas em sala de aula; perguntas estas que promovam a discussão com a turma, fomentem a procura por explicações e, mesmo, contraexemplos, a fim de se proporcionar um ambiente criativo intelectualmente. 
As interações discursivas no ensino de Física: ...

\section{Metodologia da pesquisa e análise dos dados}

Nesta pesquisa, de caráter qualitativo, analisaremos dois episódios de uma sequência didática de Física Moderna para o terceiro ano do Ensino Médio. Ela foi desenvolvida no laboratório de pesquisa em Ensino de Física (LaPEF), no trabalho de Brockington (2005). Essa atividade foi aplicada e analisada na dissertação de mestrado de Barrelo Junior (2010), cujo objetivo era verificar o desenvolvimento de processos argumentativos dos alunos a respeito do conceito de fóton ${ }^{3}$.

A sequência didática, realizada em 11 aulas, se inicia com estudos de: óptica, interferência, laser, fóton, dualidade onda-partícula e as interpretações da mecânica quântica. Ao final da sequência, pretende-se chegar à discussão das quatro linhas interpretativas da Física Quântica para a dualidade onda-partícula (a ondulatória, a corpuscular, a dualista realista e a da complementaridade). Esta discussão estará ancorada nas atividades realizadas nas aulas anteriores e, sobretudo, nas observações realizadas quando do uso, em aula, do interferômetro de Mach-Zehnder. Analisaremos episódios encontrados na aula 10 sobre as discussões, em sala, das linhas interpretativas para o interferômetro.

No conjunto dos episódios de ensino selecionados, tentaremos identificar as interações discursivas (MORTIMER; SCOTT, 2002) e os indicadores da AC propostos por Sasseron (2008). Mais especificamente, neste trabalho, buscaremos olhar: as intenções do professor no ato da fala, a abordagem comunicativa no tempo, como está sendo desenvolvida a interação verbal, e as intervenções do professor no decorrer dos episódios. As outras categorias propostas por Mortimer e Scott (2002), tais como padrão discursivo e conteúdo do discurso, serão analisadas em um outro trabalho. Aqui, as três categorias analisadas dimensionam o que o professor pretende com esta atividade e sua forma discursiva de abordar o tema. Ressaltamos, contudo, que a verificação das intençôes e das abordagens não pode ser feita por turnos, uma vez que denotam um momento da aula, perpassando, assim, diferentes turnos de interação. As intervenções, por sua vez, são analisadas na fala do professor.

Observados estes três aspectos relativos à fala do professor, buscaremos analisar quais os indicadores da Alfabetização Científica encontrados nas falas dos alunos a serem observados nos turnos. Deste modo, os dois referenciais de análise buscam classificar e entender os discursos do professor e dos alunos, respectivamente, para depois tentarem traçar um olhar mais amplo no conjunto dos episódios e da aula.

Os turnos são os momentos de fala de cada locutor. Há momentos em que uma mesma fala contém dois tipos diferentes de classificações para dado parâmetro. Nestes casos, separamos o turno em A e B. Nas transcrições, usamos um sistema de identificação para uma sequência de turno no que se refere às intenções do professor e à abordagem comunicativa, pois estas se estendem por um período. Ou seja, um conjunto de falas pode estar caracterizado dentro de uma intenção ou de uma abordagem comunicativa, conforme veremos.

${ }^{3} \mathrm{O}$ autor concedeu-nos licença para analisarmos seus dados sob outras perspectivas. 


\section{Os episódios de ensino}

De acordo com a sequência didática desenvolvida, as aulas 10 e 11 finalizam um conjunto conceitual com as linhas interpretativas da Mecânica Quântica. Ambas ocorreram juntas, na mesma data, e logo após a discussão sobre os fenômenos do interferômetro de Mach-Zehnder para o modelo quântico. Nessas duas aulas, o professor faz uma retomada sobre os fenômenos encontrados no interferômetro real e na simulação do interferômetro para o modelo quântico. Após uma apresentação sobre as linhas interpretativas da Mecânica Quântica, ele abre o debate aos alunos, sistematizando ao final da aula.

Do ponto de vista dos objetivos da aula, fica estabelecida, na sequência, que a aula 10 pretende que os alunos conheçam as linhas interpretativas. Trata-se de uma abordagem nova, baseada já nas experiências que os alunos tiveram durante a sequência, entre as quais os fenômenos de interferência para objetos quânticos no interferômetro de Mach-Zehnder. Além de apresentar essas formas interpretativas, o professor visa à percepção, por parte dos alunos, de que nenhuma delas explica completamente o comportamento do fóton de maneira satisfatória. Esse dado nos é importante na medida em que as interações caminharão de forma a realizar uma análise dos modelos, uma característica que demanda aspectos significativos da Alfabetização Científica, como a elaboração das hipóteses e o teste destas diante de um fenômeno, para tentar entendê-lo de forma geral. Ou seja, a elaboração e verificação de um modelo.

\section{$1^{\circ}$ Episódio}

O primeiro episódio situa-se entre os turnos 24 e 40 da aula. No desenvolvimento dela, o professor relembra os conteúdos estudados anteriormente, fazendo perguntas aos alunos sobre a imagem projetada do interferômetro de Mach-Zehnder para o modelo quântico (Figura 1). A intenção é fazer os alunos relembrarem para que possa ser introduzido o problema. O Quadro 1 apresenta a transcrição do episódio 1.

Figura 1. O interferômetro no simulador e real

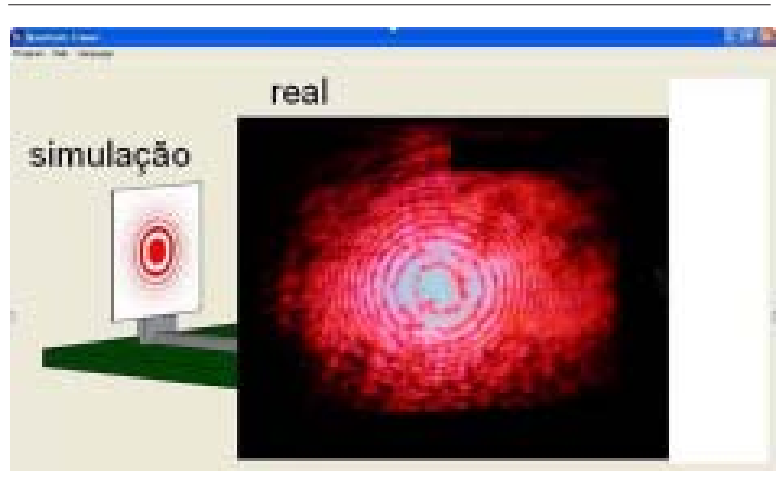

Fonte: Barrelo Junior (2010) 
As interações discursivas no ensino de Física: ...

Quadro 1. Transcrição do $1^{\circ}$ episódio, turnos 24 a 40

\begin{tabular}{|c|c|c|c|c|c|}
\hline $\mathbf{T}$ & Transcrição & Intenções & $\begin{array}{l}\text { Abordagem } \\
\text { Com. }\end{array}$ & Intervenções & $\begin{array}{l}\text { Indicadores } \\
\text { da AC }\end{array}$ \\
\hline 24 & $\begin{array}{l}\text { Professor: Todo mundo acha que é isso? Todo } \\
\text { mundo acha que é a mesma coisa? E alguém } \\
\text { sabe explicar por quê? Então olha, vamos } \\
\text { imaginar... O que vocês tão me dizendo é isso, } \\
\text { num anteparo a gente observa alguma coisa } \\
\text { parecida com isso, certo? No outro, a gente } \\
\text { vai enxergar o contrário, não é isso? Elas } \\
\text { seriam complementares porque se a gente } \\
\text { juntasse as figuras, veria o quê? }\end{array}$ & $\begin{array}{l}\text { Introduz a } \\
\text { estória } \\
\text { científica }\end{array}$ & $\begin{array}{l}\text { Interativo de } \\
\text { autoridade }\end{array}$ & $\begin{array}{l}\text { Checando/ } \\
\text { selecionando } \\
\text { significados }\end{array}$ & \\
\hline 25 & Pedro: Um círculo & & & & $\begin{array}{l}\text { Levantamento } \\
\text { de hipóteses }\end{array}$ \\
\hline 26 & $\begin{array}{l}\text { Professor: É isso. Ao invés de ver várias } \\
\text { figuras, veria um círculo. Aí, agora a } \\
\text { pergunta... Ronaldo! Alguém consegue me } \\
\text { explicar por que isso? [inaudível] Mas por quê? } \\
\text { Dá pra explicar por quê? }\end{array}$ & & & $\begin{array}{l}\text { Marcando } \\
\text { significados }\end{array}$ & \\
\hline 27 & $\begin{array}{l}\text { Pedro: [inaudível] Eu consigo explicar o que é, } \\
\text { mas porquê eu não sei. }\end{array}$ & & & & \\
\hline 28 & $\begin{array}{l}\text { Professor: Não, nós não chegamos neste } \\
\text { ponto ainda. [refere-se à explicação do que é o } \\
\text { fenômeno] }\end{array}$ & & & Dando forma & \\
\hline 29 & $\begin{array}{l}\text { Lucas: [quase inaudível, tentando explicar o } \\
\text { que está acontecendo] é igual aquela } \\
\text { experiência que a gente batia o dedo na água } \\
\text { e fazia umas ondas, elas se aumentavam, } \\
\text { aumentava não, elas ficavam juntas [entrelaça } \\
\text { os dedos das mãos] só que eu esqueci o nome } \\
\text { do fenômeno }\end{array}$ & & & & $\begin{array}{c}\text { Organização } \\
\text { de } \\
\text { Informações/ } \\
\text { Justificativa }\end{array}$ \\
\hline 30 & Professor: interferência de ondas? & & & Dando forma & \\
\hline 31 & $\begin{array}{l}\text { Lucas: É, acho que é. Só que faz mile e anos, } \\
\text { tá ligado }\end{array}$ & & & & \\
\hline 32 & $\begin{array}{l}\text { Professor: Pessoal, a gente ta dizendo aqui } \\
\text { oh... A gente ta observando nesse ponto a } \\
\text { interferência das ondas, certo? E a gente } \\
\text { enxerga aqueles pontos coloridos quando a } \\
\text { interferência é construtiva. O que significa } \\
\text { isso? As duas frentes de onda que estão se } \\
\text { encontrando, estão na mesma fase, então elas } \\
\text { se somam e você vê o ponto claro. Quando } \\
\text { elas estão em fases opostas, a gente vê o } \\
\text { que? A interferência é destrutiva, elas se } \\
\text { anulam, não é isso? O que acontece desse } \\
\text { ponto pra esse é uma inversão dessas fases, } \\
\text { tá? }\end{array}$ & & & $\begin{array}{l}\text { Marcando } \\
\text { Significados } \\
\text { (sistematiza o } \\
\text { conteúdo) }\end{array}$ & \\
\hline
\end{tabular}


Souza, V. F. M.; Sasseron, L. H.

Quadro 1. continua

\begin{tabular}{|c|c|c|c|c|c|}
\hline $\mathbf{T}$ & Transcrição & Intenções & $\begin{array}{l}\text { Abordagem } \\
\text { Com. }\end{array}$ & Intervenções & $\begin{array}{l}\text { Indicadores } \\
\text { da AC }\end{array}$ \\
\hline 33 & $\begin{array}{l}\text { Bruna: O que você ta falando é a explicação } \\
\text { do preto, é isso? }\end{array}$ & & & $\begin{array}{l}\text { Checando/ } \\
\text { selecionando } \\
\text { significado }\end{array}$ & Explicação \\
\hline 34 & Professor: Ahn? & & & & \\
\hline 35 & $\begin{array}{l}\text { Bruna: Tem inversão de fase, porque a parte } \\
\text { que reflete no semiespelho tá ... }\end{array}$ & & & & Explicação \\
\hline 36 & Professor: Tá numa fase... & & & Dando forma & \\
\hline 37 & $\begin{array}{l}\text { Bruna: numa fase diferente da que parte que } \\
\text { passou direto }\end{array}$ & & & & Explicação \\
\hline 38 & $\begin{array}{l}\text { Professor: Isso. E aí o que vai ta } \\
\text { acontecendo? Vamos supor que a fase } 1 \text { ta } \\
\text { vindo pra cá e a } 2 \text { pra cá, certo? [mostra no } \\
\text { quadro] Nesse caso aqui, eu vou pegar a } 1 \\
\text { deste, né? E vai interferir com a outra que ta } \\
\text { aqui, não é isso? Então o que ta acontecendo } \\
\text { é que ela ta pegando os lados simétricos, tudo } \\
\text { bem? Bom, aí a gente mudou pra fóton, como } \\
\text { vocês bem responderam na ultima aula, o que } \\
\text { acontece com o padrão da figura? O resultado. }\end{array}$ & & & $\begin{array}{l}\text { Marcando } \\
\text { significados }\end{array}$ & \\
\hline 39 & Lucas: Igual, mas pontinhos & & & & Classificação \\
\hline 40 & $\begin{array}{l}\text { Professor: É o mesmo, não é? O que ta } \\
\text { acontecendo só é que a gente aqui vai... } \\
\text { Quando a gente manda com o laser forma } \\
\text { imagem instantaneamente, não é isso? Todo o } \\
\text { fóton... Ele vai se distribuindo, né? E } \\
\text { dependendo da quantidade que a gente tem aí } \\
\text { a gente vai acabar observando a linha, certo? } \\
\text { Até aqui nenhuma novidade, né? Tudo bem aí, } \\
\text { Guilherme? Explica essas duas figuras aí pra } \\
\text { mim, por favor. Fala aí, Daniel. }\end{array}$ & & & $\begin{array}{l}\text { Marcando } \\
\text { significados }\end{array}$ & \\
\hline
\end{tabular}

Fonte: Elaborado pelos autores

Este primeiro episódio de análise retrata instantes iniciais da aula em que o professor discutirá com a turma as quatro interpretações da natureza da luz. Logo, a primeira fala do professor evidencia seu cuidado em organizar informações que os alunos já possuem, dadas as interações e atividades ocorridas em aulas anteriores. Trata-se, portanto, da retomada de discussões que já aconteceram e começa a revelar a intenção do professor em "introduzir a estória científica" (MORTIMER; SCOTT, 2002). Podemos observar a intenção do professor na forma como ele elabora suas perguntas e relembra os alunos das discussões e conceitos anteriores. Ele mostra, na tela, as figuras, de forma a recuperar as discussões da aula anterior e introduzir os conceitos necessários para a discussão proposta das linhas interpretativas. 
O turno 32 é uma evidência para reforçar nossa alegação de que a intenção do professor, no início desta aula, seja "introduzir os alunos na estória científica": podemos perceber nesta sua fala a retomada de conteúdos já trabalhados, como a interferência, os fótons e as figuras do interferômetro, o que demonstra sua preocupação em trazer à tona e organizar as informações importantes e necessárias para que a nova discussão possa ocorrer. Este é o primeiro passo do ciclo argumentativo proposto por Sasseron e Carvalho (2011), ou seja, são as primeiras ações nas interações discursivas, com o objetivo de se construir um argumento.

Os turnos finais deste mesmo episódio (turnos 38 e 40) também trazem evidências desta nossa proposição, uma vez que são momentos em que o professor, mais uma vez, faz referência a informações, conceitos e ideias já discutidos em aulas anteriores e que se mostram necessários para dar embasamento às discussões que virão a seguir, em outros episódios desta mesma aula.

Uma vez que as discussões giram em torno de informações de aulas anteriores, não ocorrem aqui, neste pequeno episódio, oposições de novas ideias. Neste sentido, conforme Mortimer e Scott (2002), trata-se de uma abordagem comunicativa "de autoridade", pois as referências estão intrinsecamente relacionadas à sistematização de ideias cientificamente aceitas. Vale notar que, embora no início do episódio o professor tenha feito uma pergunta de oposição de opiniões (“todo mundo acha que é isso?"), não a classificamos como uma abordagem dialógica, pois a intenção do professor, nesse instante, não é promover novos debates, mas retomar a estória científica já apresentada e discutida em outras oportunidades.

De qualquer modo, a presença de importantes colocações dos alunos nos demonstra que ocorre "interatividade" na construção do discurso. Isso fica bastante evidente nos turnos 25 e 29, por exemplo, quando encontramos, nas falas de dois alunos, indicadores da AC (SASSERON, 2008) quando eles trazem informações das aulas já ocorridas servindo, respectivamente, para embasar o levantamento de hipótese em relação à questão lançada pelo professor, para justificar uma ideia que se discute. Vale reparar ainda que, para tecer tal justificativa, o aluno Lucas, no turno 29, precisou lançar mão da organização de informações previamente trabalhadas, dando evidências da utilização de mais um indicador de AC.

Logo após esta fala do professor, a aluna Bruna coloca, diretamente para o professor, uma pergunta cujo objetivo é checar sua compreensão sobre um significado exposto na fala do professor: a interferência destrutiva de ondas. O que se vê na sequência é a própria Bruna propor uma explicação para o fenômeno: a presença deste indicador de AC (SASSERON, 2008) corrobora nossa alegação de que sua pergunta inicial tratava-se de uma verificação sobre o conceito mencionado pelo professor.

Por sua vez, como decorrência desta interatividade, o professor estabelece, com os alunos, uma cadeia de intervenções que selecionam os significados ou os marcam quando aparecem, de modo a possibilitar que os alunos sistematizem suas ideias. Parece-nos verdadeira esta observação, pois se encaixa com o momento de interatividade no qual os alunos encaminham suas respostas retomando os conceitos e marcando-os para o prosseguimento da aula.

\section{$2^{\circ}$ Episódio}

O segundo episódio aqui analisado por nós se estende do turno 67 da mesma aula até o turno 86. No período intermediário entre o episódio anterior e este, o professor continua 
Souza, V. F. M.; Sasseron, L. H.

lembrando aos alunos e começa a explicitar o problema da interferência para um fóton. Há uma digressão sobre a associação dos fenômenos do interferômetro com um laser e, no início do turno 67, o professor organiza a questão de aula para as formas de explicação. Uma breve discussão sobre as possibilidades de se explicar a natureza da luz. Posteriormente, os alunos olham quais são as formas em um quadro (Quadro 2).

Quadro 2. Transcrição do $2^{\circ}$ episódio, turnos 67 a 86.

\begin{tabular}{|c|c|c|c|c|c|}
\hline $\mathbf{T}$ & Transcrição & Intenções & $\begin{array}{c}\text { Abordagem } \\
\text { Com. }\end{array}$ & Intervenções & $\begin{array}{c}\text { Indicadores } \\
\text { da AC }\end{array}$ \\
\hline 67 & $\begin{array}{l}\text { Professor: Tá. Então, nesse caso, não tem } \\
\text { interferência e [aqui] a gente tem interferência, } \\
\text { não é isso? Bom, agora o seguinte, o que a } \\
\text { gente veio conversando ao longo do ano } \\
\text { inteirinho é que a física pode explicar as coisas } \\
\text { de duas maneiras, ou como onda ou como } \\
\text { partícula. }\end{array}$ & $\begin{array}{l}\text { Criando } \\
\text { um } \\
\text { problema }\end{array}$ & $\begin{array}{l}\text { Interativo } \\
\text { dialógico }\end{array}$ & $\begin{array}{l}\text { Selecionando } \\
\text { significados }\end{array}$ & \\
\hline 68 & Beatriz: Aluz. & & & & \\
\hline 69 & $\begin{array}{l}\text { Professor: Não, as coisas, no geral. Pra luz, } \\
\text { em particular, nós chegamos numa } \\
\text { encruzilhada. Nós chegamos numa } \\
\text { encruzilhada agora. A Bia, se eu não me } \\
\text { engano na aula passada, no finalzinho da aula, } \\
\text { colocou exatamente qual era o nosso } \\
\text { problema. Como é que eu explico, se eu } \\
\text { pensar que a luz é uma partícula e o fóton é } \\
\text { uma partícula, como é que eu explico a } \\
\text { interferência pra um único fóton? Então, é isso } \\
\text { que a mecânica quântica vai tentar conversar } \\
\text { com a gente. }\end{array}$ & & & & \\
\hline 70 & Vitor: explicar como eles passam. & & & & \\
\hline 71 & $\begin{array}{l}\text { Professor: Não, um único. Como é que um } \\
\text { fóton interfere com ele mesmo. [inaudível, } \\
\text { vários alunos falam ao mesmo tempo] Não, } \\
\text { não, peraí. Pessoal, diferente do que eles tão } \\
\text { dizendo aqui, não é quando a gente tem assim, } \\
\text { ah, eu tenho a luz interagindo com outra coisa, } \\
\text { aí você ta aumentando as variáveis. Nós } \\
\text { estamos pensando assim, olha... Foi isso que } \\
\text { a Bia discutiu aqui na ultima aula. Como é que } \\
\text { eu explico interferência para um único fóton? } \\
\text { Ele com ele mesmo. Na nossa figurinha lá, se } \\
\text { eu lançar apenas um único fóton, entendeu? } \\
\text { Diferente do que a gente tinha no real, que a } \\
\text { gente manda um feixe, a gente ta mandando } \\
\text { milhões ao mesmo tempo e aí eu posso } \\
\text { continuar pensando em bolinhas colidindo uma } \\
\text { com a outra, né? Agora não, eu tenho um } \\
\text { único E nesse único eu continuo tendo } \\
\text { interferência. }\end{array}$ & & & $\begin{array}{c}\text { Revendo o } \\
\text { progresso da } \\
\text { estória } \\
\text { científica }\end{array}$ & \\
\hline
\end{tabular}


As interações discursivas no ensino de Física: ...

Quadro 2. continua

\begin{tabular}{|c|c|c|c|c|c|}
\hline $\mathbf{T}$ & Transcrição & Intenções & $\begin{array}{l}\text { Abordagem } \\
\text { Com. }\end{array}$ & Intervenções & $\begin{array}{l}\text { Indicadores } \\
\text { da AC }\end{array}$ \\
\hline 72 & Beatriz: Ele se dividiu ao meio. & & & & $\begin{array}{l}\text { Levantamento } \\
\text { de hipótese }\end{array}$ \\
\hline 73 & $\begin{array}{l}\text { Professor: Quando ele passa lá no } \\
\text { semiespelho ele se divide em duas partes? }\end{array}$ & & & Dando forma & \\
\hline 74 & Beatriz: $E_{\ldots} .$. & & & & \\
\hline 75 & $\begin{array}{l}\text { Professor: Mas duas partes do que? De } \\
\text { partícula? Duas partes de onda? Uma parte } \\
\text { partícula outra parte onda? }\end{array}$ & & & Checando & \\
\hline 76 & Beatriz: Acho que as duas partes partícula. & & & & $\begin{array}{l}\text { Levantamento } \\
\text { de hipótese }\end{array}$ \\
\hline 77 & $\begin{array}{l}\text { Professor: Mas aí se ele se dividir ao meio, eu } \\
\text { deixo de ter um fóton e tenho dois. Dois meio } \\
\text { fótons... }\end{array}$ & & & Dando forma & \\
\hline 78 & Beatriz: Aí depois eles se juntam. & & & & $\begin{array}{l}\text { Levantamento } \\
\text { de hipótese }\end{array}$ \\
\hline 79 & Professor: Junta aqui embaixo de novo? & & & Dando forma & \\
\hline 80 & Beatriz: É, os dois lados. & & & & Previsão \\
\hline 81 & $\begin{array}{l}\text { Professor: mas como é que com eles juntos eu } \\
\text { posso ter no anteparo dos dois lados? Aqui... } \\
\text { Olha, a Bia ta dizendo o seguinte, aqui ele se } \\
\text { divide, certo? Aí vem pra cá e vem pra cá. } \\
\text { Quando chega aqui, se eles se juntam, como a } \\
\text { Bia ta falando, eu teria que ter observação em } \\
\text { um único anteparo, mas eu consigo medir nos } \\
\text { dois ao mesmo tempo. }\end{array}$ & & & Dando forma & \\
\hline 82 & $\begin{array}{l}\text { Bruna: Eu estava pensando que ali no meio } \\
\text { eles se dividem de novo... }\end{array}$ & & & & $\begin{array}{l}\text { Levantamento } \\
\text { de hipótese }\end{array}$ \\
\hline 83 & Professor: Meninos, por favor! & & & & \\
\hline 84 & $\begin{array}{l}\text { Bruna: Vai passar uma parte ali e a outra vai } \\
\text { por ali, ó [aponta a figura] }\end{array}$ & & & & $\begin{array}{l}\text { Teste de } \\
\text { hipótese }\end{array}$ \\
\hline 85 & $\begin{array}{l}\text { Professor: Dois que vem pra cá e dois que } \\
\text { vem pra cá? }\end{array}$ & & & Dando forma & \\
\hline 86 & Bruna: Não sei, mas foi o que pensei. & & & & Previsão \\
\hline
\end{tabular}

Fonte: Elaborado pelos autores

Logo no início deste segundo episódio selecionado para análise, nos turnos 69 e 71, após uma brevíssima menção ao que havia sido discutido no ano todo até então, coloca-se muito claramente qual o problema que devem discutir agora: como explicar o fenômeno de 
Souza, V. F. M.; Sasseron, L. H.

interferência, produzido pelo interferômetro de MZ, quando imaginamos as interações sofridas por um único fóton. É com falas como as que ali estão colocadas que percebemos a intenção do professor em "criar um problema” (MORTIMER; SCOTT, 2002).

No turno 69, o professor explicita o problema quando se refere à luz com "chegamos a uma encruzilhada". A partir da criação do problema para explicar os fenômenos do interferômetro, um grande número de perguntas, respostas, prosseguimentos nos evidenciando uma abordagem "interativa". Dos turnos 71 até o 86 o professor interage com os alunos fazendo perguntas, explora a visão dos estudantes, não coloca nada como certo, permite a investigação, contrapõe ideias, dialoga com as posições dos alunos. Esta postura discursiva evidencia uma abordagem além de interativa, dialógica.

Esta abordagem dialógica entre o professor e os alunos, no decorrer do problema, aparece de maneira forte pelas perguntas e respostas. O professor intervém predominantemente "dando forma" às respostas dos alunos. A partir da questão feita e refeita pelo professor, os alunos começam a explicitar indicadores de AC no levantamento de hipóteses (SASSERON, 2008), acenando para possíveis explicações, ou melhor, hipóteses que revelam claramente a tentativa de trazerem evidências que possam ser consideradas de modo a conseguirem fundamentar a explicação para o fenômeno que estão investigando.

Diferentemente do que ocorreu no primeiro episódio aqui analisado, agora, devido à pergunta colocada pelo professor, ou seja, devido à problematização por ele criada no intuito de que os alunos busquem encontrar relações entre as variáveis importantes do processo investigado, as interações entre professor e alunos configuram-se como sendo do tipo "interativasdialógicas". Este fato traz-nos suporte que corrobora a ideia de que um ciclo argumentativo (SASSERON; CARVALHO, 2011) ocorre na construção de significados em sala de aula na interação entre professor e alunos: tendo, anteriormente, explicitado as informações relevantes e discriminado as variáveis relevantes para o fenômeno em questão, trata-se, agora, de promover debate que leve os alunos a tecerem relação entre estas variáveis: é este o problema no qual se baseia esta aula e, portanto, é por este motivo que as interações são agora dialógicas, uma vez que o conceito-chave da aula está ainda em construção pelos alunos.

\section{Considerações finais sobre a análise}

Os dois episódios têm natureza de discurso distinta, conforme pudemos observar nas classificações dos discursos do professor e dos alunos. Ao observar o discurso do professor, por um lado, e os indicadores da AC presentes na fala dos alunos, por outro, observamos, nos dois episódios, confluências nas categorias e nos momentos de interação. No primeiro episódio, o discurso interativo de autoridade predomina na ação do professor. Ele, relembrando os alunos sobre os conceitos das aulas anteriores, molda significados, marca, faz questões sobre a aula anterior e introduz a estória científica. Relembra o conceito de interferência e os fenômenos ocorridos no interferômetro de Mach-Zehnder. Os alunos, em resposta a esta interação, apresentam uma grande quantidade de indicadores de explicação e classificação, exatamente pelo trato com os dados. Neste sentido, nos parece relevante o discurso interativo de autoridade como um momento de tomada de consciência dos dados do problema, que se tornará fundamental para a criação de um argumento. Diferente de uma primeira impressão, 
nem sempre o discurso de autoridade representa um momento imperativo do professor pelos alunos; neste caso, foi importante para o desenvolvimento da aula. Mas nos parece, também, que foi importante diante da intenção do professor, pois, naquele momento, sua intenção era introduzir o problema e, para isso, assumir o discurso e orientar o desenvolvimento da aula para a construção de um problema em um momento posterior.

Tanto nos parece verdadeira a importância da intenção do professor no discurso que, no segundo episódio, ao criar constantemente o problema da explicação para as linhas de interferência para o modelo quântico, o professor estabelece uma abordagem comunicativa dialógica, pois exatamente quer que os alunos tentem explicar como as linhas de interferência aparecem no modelo quântico. Vimos aqui uma coerência, pois se a abordagem fosse de autoridade, o problema seria resolvido ou interrompido diante de uma visão unilateral. E, como consequência da proposição constantemente problematizadora no discurso, os alunos são impelidos a responder, a elaborar hipóteses diante do problema, discutir, testar suas hipóteses e argumentar. Essa nos parece, também, uma conclusão importante: na medida em que propomos um problema, as possibilidades de resolvê-lo aparecerão pelos alunos. Assim, para um ensino de Física, se iniciará um processo de investigação, comum ao ensino de Física, que leve o aluno a argumentar e, consequentemente, a Alfabetização Científica.

Uma observação ainda acerca da interatividade entre professor e alunos é a de que muitos dos indicadores de classificação usados por Mortimer e Scott (2002), para o professor, são manifestados também pelos alunos. No turno 32 do primeiro episódio, por exemplo, a aluna Bruna intervém junto à sala checando um significado. O que nos chama a atenção é que este tipo de intervenção, na proposta de Mortimer e Scott (2002), está intrinsecamente ligada ao professor como intermediador da argumentação, mas aqui, na fala da aluna, configura-se como uma forte evidência de que o discurso em sala é, de fato, dialógico, e não só o professor opera o discurso. Sob este aspecto, ainda preliminar, é possível se traçarem desdobramentos em outras pesquisas para verificar as ocorrências dos indicadores discursivos de Mortimer e Scott (2002) nas falas especificamente dos alunos.

Observamos ainda, diante dos dados, que momentos de introdução requerem a retomada de dados e dos conhecimentos dos alunos acerca do assunto, isto nos foi mostrado no primeiro episódio. Momentos de criação de problema repercutem em elaboração e teste de hipóteses por parte dos alunos, exatamente na tentativa de resolver o problema proposto, como nos mostrou o segundo episódio. Observando o caminho destes dois episódios em relação à proposta da aula, parece haver um caminho mais amplo do discurso e de possibilidades de indicadores da alfabetização diferentes no decorrer da aula. Tendo em vista que os dois episódios situam-se em uma mesma aula, dois momentos distintos do ponto de vista discursivo parecem estar contidos dentro da proposta da aula. Uma retomada conceitual demandou aspectos discursivos diferentes da criação de um problema, da discussão ou de uma sistematização. Estes são elementos relacionados ao Ciclo Argumentativo operantes no desenvolvimento da aula, ou seja, um caminho de acordo com as intenções amplas do professor pode demandar a utilização de determinados indicadores das interações discursivas. Devemos levar em conta, entretanto, a estrutura da sequência didática para este caso em particular. Parece-nos válido, contudo, dar continuidade a esse olhar em projetos futuros.

Outro aspecto que merece atenção é o fato de que, em todos os episódios e em toda a aula, a abordagem interativa demanda perguntas e, mesmo com intenções diferentes, a per- 
Souza, V. F. M.; Sasseron, L. H.

gunta se torna o elemento pelo qual o professor caminha para o desenvolvimento da aula. Pretendemos nos dedicar a este assunto em pesquisas futuras, tentando entender como as perguntas em específico podem ser usadas no conjunto das interações discursivas entre professor e alunos.

Por fim, conforme tentamos encaminhar, por meio do referencial adotado, o discurso do professor na sala de aula e a resposta a esse discurso, por parte dos alunos, estão intimamente ligados. Por se tratar de um fenômeno comunicativo, a sala de aula é um ambiente de diálogo, de interação e de troca. Para além dessa perspectiva, tentando relacionar o discurso do professor com a fala dos alunos, pudemos perceber uma relação de causa e efeito entre estes dois para os objetivos da aula e com o aparecimento de aspectos da Alfabetização Científica. Há, portanto, indícios de que a utilização de determinados tipos de discurso pode ajudar a promover a Alfabetização Científica dos alunos. E, se temos esse como pressuposto basilar do Ensino de Física, podemos dirigir olhares mais próximos para as características do discurso do professor, tais como: suas perguntas, seus gestos, sua forma de abordagem etc. E, neste sentido, abre-se uma possibilidade de pesquisa que pretendemos investigar.

\section{Referências}

ASTOLFI, J. P. Quelle formation scientifique pour l'école primaire? Didaskalia, Lisboa, n. 7, p. 105-112, 1995.

AULER, D.; DELIZOICOV, D. Alfabetização científico-tecnológica para quê? Ensaio: Pesquisa em Educação em Ciências, Belo Horizonte, v. 3, n. 2, p. 105-116, 2001.

BAKHTIN, M. M. Estética da criação verbal. 3. ed. São Paulo: Martins Fontes, 2000.

BARRELO JUNIOR, N. Argumentação no discurso oral e escrito de alunos do ensino médio em uma sequência didática de física moderna. 2010. 112 f. Dissertação

(Mestrado em Educação) - Faculdade de Educação, Universidade de São Paulo, São Paulo, 2010.

BINGLE, W. H.; GASKELL, P. J. Scientific literacy for decision making and the social construction of science knowledge. Science Education, Hoboken, v. 78, n. 2, p. 185-201, 1994.

BRANDI, A. T. E.; GURGEL, C. M. A. A alfabetização científica e o processo de ler e escrever em séries iniciais: emergências de um estudo de investigação-ação. Ciência \& Educação, Bauru, v. 8, n. 1, p. 113-125, 2002.

BROCKINGTON, G. A realidade escondida: a dualidade onda-partícula para estudantes do Ensino Médio. 2005. 268 f. Dissertação (Mestrado em Ensino de Ciências, modalidade Física e Química) - Programa Interunidades, Universidade de São Paulo, São Paulo, 2005.

BYBEE, R. W. Achieving scientific literacy. The Science Teacher, Arlington, v. 62, n. 7, p. 28-33, 1995. 
As interações discursivas no ensino de Física: ...

BYBEE, R. W.; DeBOER, G. E. Research on goals for the science curriculum. In: GABEL, D. L. (Ed.). Handbook of research in science teaching and learning. New York: McMillan, 1994. p. 357-387.

CAJAS, F. Alfabetización científica y tecnológica: la transposición didactica del conocimiento tecnológico. Enseñanza de las Ciencias, Barcelona, v. 19, n. 2, p. 243-254, 2001.

CARVALHO, A. M. P. Building up explanations in physics teaching. International Journal of Science Education, Abingdon, v. 26, n. 2, p. 225-237, 2004.

. Enculturação científica: uma meta do ensino de ciências. In: TRAVESSINI, C. et al. (Org.). Trajetórias e processos de ensinar e aprender: práticas e didáticas. Porto Alegre: EDIPUCRS, 2008. v. 2. p. 115-135.

CARVALHO, A. M. P.; TINOCO, S. C. O Ensino de ciências como "enculturação". In: CATANI, D. B.; VICENTINI, P. P. (Org.). Formação e autoformação: saberes e práticas nas experiências dos professores. São Paulo: Escrituras, 2006. p. 251-255.

CHASSOT, A. Alfabetização científica: questões e desafios para a educação. Ijuí: Editora da Unijuí, 2000.

DÍAZ, J. A. A.; ALONSO, A. V.; MAS, M. A. M. Papel de la educación CTS en una alfabetización científica y tecnológica para todas las personas. Revista Electrónica de Enseñanza de las Ciencias, v. 2, n. 2, 2003.

DRIVER, R.; NEWTON, P.; OSBORNE, J. Establishing the norms of scientific argumentation in classrooms. Science Education, Hoboken, v. 84, n. 3, p. 287-312, 2000.

FOUREZ, G. Alphabétisation scientifique et technique: essai sur les finalités de l'enseignement des sciences. Bruxelles: DeBoeck-Wesmael, 1994.

. Crise no ensino de ciências? Investigações em Ensino de Ciências, Porto alegre, v. 8, n. 2, p. 109-123, 2003.

. L'enseignement des sciences en crise. Le Ligueur, Bruxelles, n. 15, p. 2, avr. 2000.

FREIRE, P. Educação como prática da liberdade. Rio de Janeiro: Paz e Terra, 1980.

GIL-PÉREZ, D.; VILCHES-PEÑA, A. Una alfabetización científica para el siglo XXI: obstáculos y propuestas de actuación. Investigación en la Escuela, Sevilla, v. 43, n. 1, p. 27-37, 2001.

GIL-PÉREZ, D. et al. Questionando a didática de resolução de problemas: elaboração de um modelo alternativo. Caderno Catarinense de Ensino de Física, Florianópolis, v. 9, n. 1, p. 7- 19, 1992.

HURD, P. D. Scientific literacy: new minds for a changing world. Science Education, Hoboken, v. 82, n. 3, p. 407-416, 1998. 
Souza, V. F. M.; Sasseron, L. H.

JIMÉNEZ-ALEIXANDRE, M. P.; BUGALLO RODRÍGUEZ, A.; DUSCHL, R. A. "Doing the lesson" or "doing science": argument in high school genetics. Science Education, Hoboken, v. 84, n. 6, p. 757-792, 2000.

KLEIMAN, A. B. Modelos de letramento e as práticas de alfabetização na escola. In: KLEIMAN, A. B. (Org.). Os significados do letramento: uma nova perspectiva sobre a prática social da escrita. Campinas: Mercado das Letras, 1995. p. 15-61.

LAUGKSCH, R. C. Scientific literacy: a conceptual overview. Science Education, Hoboken, v. 84, n. 1, p. 71-94, 2000.

LEMKE, J. Multiplying meaning: visual and verbal semiotics in scientific text. In: MARTIN, J.; VEEL, R. (Ed.). Reading science: critical and functional perspectives on the discourses of science. London: Routledge, 1998. p. 87-113.

LORENZETTTI, L.; DELIZOICOV, D. Alfabetização científica no contexto das séries iniciais. Ensaio: Pesquisa em Educação em Ciências, Belo Horizonte, v. 3, n. 1, p. 37-50, mar. 2001.

MAMEDE, M.; ZIMMERMANN, E. Letramento científico e CTS na formação de professores para o ensino de física. In: SIMPÓSIO NACIONAL DE ENSINO DE FÍSICA, 16., 2005, Rio de Janeiro. Anais... São Paulo: Sociedade Brasileira de Física, 2005. Disponível em: <http://www.sbf1.sbfisica.org.br/eventos/snef/xvi/cd/ listatrabcompleta.html>. Acesso em: 20 out. 2006.

MARTINS, I.; OGBORN, J.; KRESS, G. Explicando uma explicação. Ensaio: Pesquisa em educação em Ciências, Belo Horizonte, v. 1, n. 1, p. 1-14, 1999.

MEMBIELA, P. Sobre la deseable relación entre comprensión pública de la ciência y alfabetización científica. Tecne, Episteme y Didaxis, Bogota, n. 22, p. 107-111, 2007.

MILLAR, R.; OSBORNE, J. Beyond 2000: science education for the future. London: King's College, 1998. Disponível em: < http://www.nuffieldfoundation.org/beyond-2000science-education-future >. Acesso em: 11 mar. 2011.

MORTIMER, E. F.; SCOTT, P. Atividade discursiva nas salas de aula de ciências: uma ferramenta sociocultural para analisar e planejar o ensino. Investigações em Ensino de Ciências, Porto Alegre, v. 7, n. 3, p. 283-306, 2002. Disponível em: <http:// www.if.ufrgs.br/public/ensino/vol7/n3/v7_n3_a7.htm>. Acesso em: 29 abr. 2007.

MORTIMER, E. F.; MACHADO, A. H. A linguagem em uma aula de ciências. Presença Pedagógica, Belo Horizonte, v. 2, n. 11, p. 49-57, 1996.

NASCIMENTO, S. S.; VIEIRA, R. D. Uma visão integrada dos procedimentos discursivos didáticos de um formador em situações argumentativas de sala de aula. Ciência $\boldsymbol{\&}$ Educação, Bauru, v. 15, n. 3, p. 1-15, 2009.

NORRIS, S. P.; PHILLIPS, L. M. How literacy in its fundamental sense is central to scientific literacy. Science Education, Hoboken, v. 87, n. 2, p. 224-240, 2003. 
As interações discursivas no ensino de Física: ...

OLSON, S.; LOUCKS-HORSLEY, S. (Ed.). Inquiry and the national science education standards: a guide for teaching and learning. Washington: Committee on the Development of an Addendum to the National Science Education Standards on Scientific Inquiry, National Research Council, 2000. Disponível em: <http://www.nap.edu/ catalog.php?record_id=9596>. Acesso em: 04 mar. 2011.

RODRIGUES, T. A.; BORGES, A. T. O ensino de ciências por investigação: reconstrução histórica. In: ENCONTRO DE PESQUISA EM ENSINO DE FÍSICA, 11., 2008, Curitiba. Atas... Curitiba: SBF, 2008. Disponível em: < http://www.sbf1.sbfisica.org.br/ eventos/epef/xi/atas/listaresumos.htm>. Acesso em: 13 jun. 2012

ROTH, W. M. Competent workplace mathematics: how signs become transparent.

International Journal of Computers for Mathematical Learning, Dordrecht, v. 8, n. 3, p. 161-189, 2003.

SANTOS, W. L. P.; MORTIMER, E. F. Tomada de decisão para ação social responsável no ensino de ciências. Ciência \& Educação, Bauru, v. 7, n. 1, p. 95-111, 2001.

SASSERON, L. H. Alfabetização científica no ensino fundamental: estrutura e indicadores deste processo em sala de aula. 2008. 180 f. Tese (Doutorado em Educação) Faculdade de Educação, Universidade de São Paulo, São Paulo, 2008.

SASSERON, L. H.; CARVALHO, A. M. P. Almejando a alfabetização científica no Ensino Fundamental: a proposição e a procura de indicadores do processo. Investigações em Ensino de Ciências, Porto alegre, v. 13, n. 3, p. 333-352, 2008.

. Construindo argumentação na sala de aula: a presença do ciclo argumentativo, os indicadores de alfabetização científica e o padrão de Toulmin. Ciência \& Educação, Bauru, v. 17, n. 1, p. 97-114, 2011.

SOARES, M. Letramento: um tema em três gêneros. Belo Horizonte: Autêntica, 1998.

VYGOTSKY, L. S. Pensamento e linguagem. 2. ed. São Paulo: Martins Fontes, 2000. 